\title{
UN FRAGMENTO DE LA HISTORIA CONTEMPORÁNEA. LA BOMBA ATÓMICA Y LOS FÍSICOS DE LOS ÁLAMOS
}

\section{A FRAGMENT OF CONTEMPORARY HISTORY. THE ATOMIC BOMB AND PHYSICISTS AT LOS ALAMOS}

José Canosa: Universidad de Harvard (Estados Unidos) jose.canosa@mixmail.com

\section{CURRÍCULUM VITAE}

Doctor en Física Aplicada por la Universidad de Harvard (Estados Unidos) fue investigador en el Centro Científico de IBM en Palo Alto en California (Estados Unidos).

\section{RESUMEN}

Este artículo es un fragmento de historia contemporánea en el que se muestra la relación existente entre la odisea de un emigrante asturiano, la Gran Depresión en Estados Unidos, la Guerra Civil Española, algunos físicos de Los Álamos, la primera bomba atómica y la prueba nuclear norcoreana de octubre de 2006. Las bombas arrojadas sobre Hiroshima y Nagasaki a principios de agosto de 1945 fueron desarrolladas en el laboratorio de Los Álamos (Nuevo Méjico). El Proyecto Manhattan reunió a los mejores científicos americanos y europeos, entre ellos J. Robert Oppenheimer. 


\title{
PALABRAS CLAVE
}

Bomba Atómica - Gran Depresión - Científico - Prueba nuclear

\begin{abstract}
This article is a piece of contemporary history which shows the relationship between the odyssey of an immigrant Asturian, the Great Depression in America, the Spanish Civil War, some physicists at Los Alamos, the first atomic bomb and the nuclear test North Korea's October 2006. The bombs dropped on Hiroshima and Nagasaki in early August 1945 were developed in the laboratory at Los Alamos (New Mexico). The Manhattan Project brought together the best American and European scientists, including J. Robert Oppenheimer.
\end{abstract}

\section{KEY WORDS}

Atomic Bomb - Depression - Science - Nuclear Test

\section{TEXTO}

Este artículo es un fragmento de historia contemporánea en el que se muestra la relación existente entre la odisea de un emigrante asturiano, la Gran Depresión en Estados Unidos, la Guerra Civil Española, algunos físicos de Los Álamos, la primera bomba atómica y la prueba nuclear norcoreana de octubre de 2006.

Las bombas arrojadas sobre Hiroshima y Nagasaki a principios de agosto de 1945 fueron desarrolladas en el laboratorio de Los Álamos (Nuevo Méjico), creado para 
este fin a principios de 1943. El Proyecto Manhattan, financiado con el 2\% del PIB norteamericano, logró su objetivo en poco más de dos años: la primera explosión nuclear tuvo lugar el 16 de julio de 1945, en el desierto de Nuevo Méjico.

El Proyecto Manhattan reunió a los mejores científicos americanos y europeos; la mayoría de estos últimos eran refugiados de Hitler y el fascismo, y sabían exactamente lo que estaba en juego: ¿quién se hacía primero con la bomba, los nazis o ellos? Muchos eran investigadores básicos, y abandonaron el trabajo fundamental para acometer el trabajo aplicado de determinar las propiedades físicas esenciales del uranio y del plutonio, desarrollar métodos para producir esos materiales en gran escala y, por último, diseñar y construir la bomba. La práctica totalidad abandonó Los Álamos al terminar la guerra y regresó a la universidad. Y no pocos obtuvieron el Nobel, bien el de Física, bien el de Química.

Como otros científicos clave del Manhattan (Lawrence, Seaborg, McMillan, Segre, Álvarez, todos ellos premios Nobel), J. Robert Oppenheimer, director científico de Los Álamos, fue profesor de física en la Universidad de California en Berkeley durante la década terrible de los años 30, en la que EEUU estuvo sumido en la Gran Depresión, el acontecimiento más traumático del siglo XX para ese país. El paro alcanzó al 25\% de la población activa, y la Seguridad Social sólo empezó a introducirse a partir de 1935. Hubo un tiempo en que quien no tenía trabajo no tenía medios de subsistencia. 


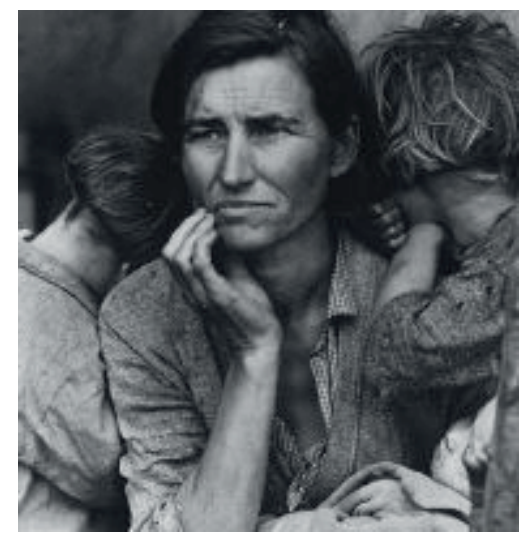

Algunas fotografías muestran colas interminables de gentes esperando recibir un plato caliente en las cocinas instaladas por el Gobierno. Dorothea Lange tomó la imagen más dramática de la Depresión en 1936 y en California: Migrant Mother. En ella se ve a una mujer de 32 años con dos de sus siete hijos y una expresión de desolación total, porque acaba de vender los neumáticos de su viejo coche para comprar comida, una situación descrita en la famosa novela Las uvas de la ira, de John Steinbeck.

Oppenheimer, como otros profesores e intelectuales de la época, reaccionó ante este desastre adoptando ideas izquierdistas y asistiendo a reuniones del Partido Comunista. Aunque nunca se sacó el carné, su hermano, su mujer y una antigua novia sí habían sido miembros del PC. En los años 30 esto no era nada especial, sobre todo en la Universidad de California en Berkeley, donde había una corriente izquierdista de apoyo a la causa de la República en la guerra civil española.

La mujer de Oppenheimer había sido la viuda de Joseph Dallet, un miembro del PC que murió en España en 1937, combatiendo con las Brigadas Internacionales. En sus memorias (A Life in Our Times), John Kenneth Galbraith relata su admiración por Robert Merriman, colega suyo en Berkeley e instructor de economía, el cual 
aprovechó una beca de viaje y su entrenamiento militar (en el programa universitario de formación de oficiales de reserva) para dirigirse a España y ponerse al frente de la Brigada Abraham Lincoln; luego fue jefe del Estado Mayor de la XV Brigada Internacional.

Merriman murió en la retirada de Belchite, en 1938, pero su memoria pervive en el personaje de Robert Jordan, el héroe de Por quién doblan las campanas, de Hemingway.

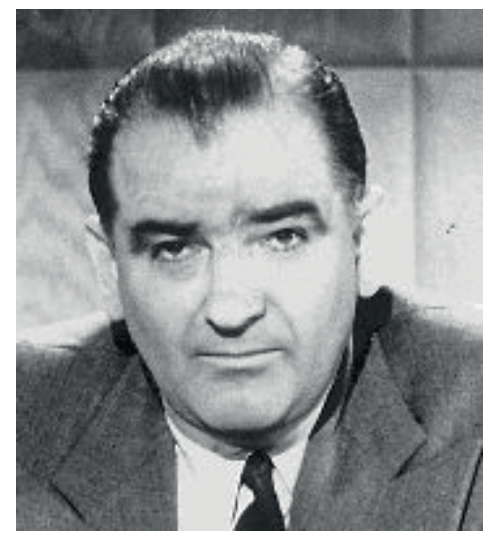

Después de la guerra, Oppenheimer, que presidía el Comité Consultivo de la Comisión para la Energía Atómica, se opuso por razones de conciencia al programa que conduciría al desarrollo de la bomba de hidrógeno. Como no creía en los motivos de conciencia de Stalin y estaba informado de que los rusos podían hacerse con la bomba, el presidente Truman dio la orden de poner en marcha el proyecto.

En 1952, durante el macartismo y la guerra de Corea, Oppenheimer fue sometido a una serie de audiencias secretas por parte de la Comisión para la Energía Atómica, tendentes a probar que era un riesgo para la seguridad nacional. Se desenterraron sus simpatías izquierdistas de los años 30 y sus asociaciones con comunistas, aunque 
estos antecedentes eran ya conocidos cuando fue nombrado director científico de Los Álamos.

Mientras estuvo al frente del célebre laboratorio de Nuevo Méjico, Oppenheimer demostró su devoción al país. Todos sus colegas afirmaron que su lealtad estaba fuera de duda. Sólo Teller declaró en su contra. Teller era un físico nacido en Hungría que tenía un odio visceral a la Unión Soviética, que había ocupado su país, y era conocido como "el padre de la bomba de hidrógeno".

En 1953 fue revocada la autorización de seguridad (security clearance) de Oppenheimer, y éste quedó excluido para siempre de los consejos de gobierno. Con todo, su prestigio era tal que fue nombrado director del Instituto de Estudios Avanzados de Princeton, institución privada en la que trabajaba Einstein. El presidente Johnson lo rehabilitó en 1963, en una ceremonia pública en la Casa Blanca, en la que le entregó el premio Enrico Fermi. Murió en 1967.

Los dos explosivos nucleares para la bomba eran el uranio-235, obtenido en las enormes instalaciones de difusión gaseosa de Oak Ridge (Tennessee), y el plutonio239, obtenido en los reactores de producción de Hanford (estado de Washington). Debido a las propiedades físicas del uranio-235, el diseño de la bomba fue relativamente fácil. Estaba basado en el cañón (se dispara dentro de un tubo una masa del explosivo nuclear contra otra, para así alcanzar la masa crítica y producir la detonación). Al principio se creyó que el diseño basado en el cañón serviría también para "ensamblar" la bomba de plutonio, pero el trabajo de Emilio Segre (premio Nobel en 1959 y discípulo de Fermi) sobre la fisión espontánea del plutonio estableció que, antes de que las dos masas de éste se juntaran, se produciría una predetonación muy poco eficiente. 


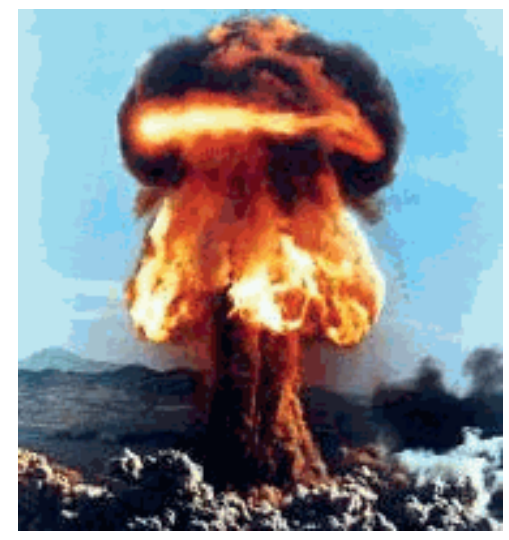

La inmensa inversión en los reactores de Hanford sería inútil si no se encontraba un método para ensamblar la bomba de plutonio. Aquí es cuando entra en escena Luis Walter Álvarez, Nobel de Física en 1968. Se determinó que un método posible era el de la implosión, es decir, rodear una esfera sólida de plutonio con otra esfera hueca de explosivos convencionales que, al explotar, producirían una onda compresiva esférica dirigida hacia el interior, es decir, a la esfera de plutonio. La esfera, sometida a altísimas presiones, se comprimiría en otra mucho más densa, que alcanzaría la masa crítica y produciría la explosión nuclear.

Luis Álvarez fue quien diseñó el detonador de la bomba de plutonio. No obstante, el detonador era tan complejo que se estimó necesario hacer una explosión de prueba, para asegurarse de que funcionaba. Así pues, se detonó una bomba en Nuevo Méjico (la explosión de que hablábamos al principio de este artículo); sobre Nagasaki se arrojó otra de igual diseño, la denominada Fat Man.

La prueba que realizaron los norcoreanos el 6 de octubre de 2006 consistió en la explosión de una bomba de plutonio. Su muy baja potencia (medio kilotón; la de Nuevo Méjico fue de 20 kilotones) hizo sospechar a los expertos norteamericanos que el detonador de implosión no funcionó correctamente. Un kilotón es equivalente a 1.000 toneladas de TNT. La detonación de los explosivos convencionales que rodean 
al núcleo de plutonio tiene que producir una onda esférica de compresión perfectamente simétrica. Cualquier asimetría, debida a diferencias de nanosegundos en los tiempos de explosión de los diferentes elementos explosivos, puede causar una explosión (predetonación) muy poco eficiente.

Siempre me han intrigado los orígenes de Luis Álvarez, un individuo de raza blanca nacido en San Francisco en 1911. Probablemente no procedía de Méjico o Suramérica. $\mathrm{Ni}$ en su autobiografía, ni en las varias biografías que he consultado sobre el personaje, se mencionan sus antecedentes familiares. Hablé con un antiguo colaborador suyo en el laboratorio de Livermore, y tampoco sabía nada, pero me sugirió que me pusiera en contacto con el hijo de aquél, Walter Álvarez, profesor de Geología en Berkeley. Y fue Walter quien me reveló la historia de su familia, que bien podría ser el eje de una novela épica.

El abuelo de Luis Álvarez, Luis Fernández Álvarez, nació en Asturias, cerca de Salas. Huérfano de padre y madre, emigró a Cuba cuando contaba 13 años. Posteriormente recaló en EEUU, y a los 34 se graduó como médico en California. Ejerció la medicina durante tiempo en Hawai (y descubrió una nueva prueba diagnóstica para la lepra macular), donde nacieron sus cinco hijos.

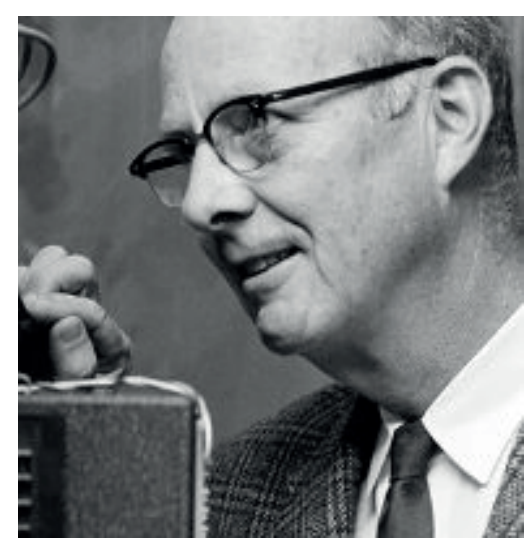


Regresó a California en 1906, y fue cónsul de España en Los Ángeles durante mucho tiempo. Su hija más joven, Mabel (1891-1985), fue una reputada pintora: en la actualidad, sus cuadros alcanzan precios bastante elevados. Otro de sus hijos, Walter C., fue profesor de Medicina en la Universidad de Minnesota y un médico destacado de la Clínica Mayo de Rochester. El Dr. Álvarez, el padre de Luis, ayudó a recaudar fondos para uno de los ciclotrones de Lawrence. Tras obtener el doctorado en Física (Chicago, 1936), Luis trabajó con el propio Lawrence en Berkeley, donde transcurrió toda su vida profesional.

Luis Álvarez nunca mostró interés por sus orígenes españoles; en cambio, su hijo Walter, el geólogo de Berkeley, me dijo que está "muy interesado en su familia española", a la que ha visitado un par de veces.

Luis Álvarez fue un fenómeno imposible de catalogar. Durante la guerra, antes de su etapa en Los Álamos, trabajó en el Laboratorio de Radiación del Instituto Tecnológico de Massachusetts (MIT), donde inventó un sistema de radar para aterrizajes de aviones sin visibilidad. Luego diseñó un acelerador lineal para producir haces de protones de elevada intensidad. Fue codescubridor del tritio (isótopo del hidrógeno), y obtuvo el Nobel por su trabajo sobre partículas elementales con una cámara de burbujas de hidrógeno.

Junto con su hijo Walter, en 1980 formuló la teoría de que la extinción de los dinosaurios se produjo hace unos 65 millones de años debido al impacto de un cometa o meteorito gigante y a la catástrofe ecológica provocada por el oscurecimiento de la atmósfera. Esta teoría es aceptada en la actualidad, después del descubrimiento de un cráter gigante en la península de Yucatán (Méjico) que data de la misma época. El trabajo sobre los dinosaurios está descrito en el libro de Walter Tyrannosaurus rex y el cráter de la muerte (Grijalbo Mondadori). 


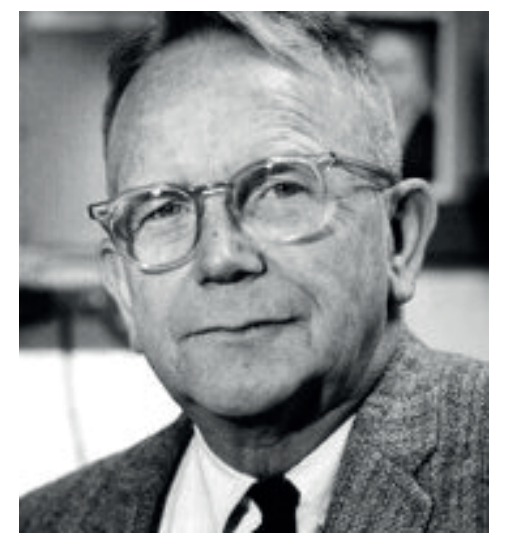

Aunque no fue uno de los personajes famosos de Los Álamos, Kenneth Bainbridge, un físico nuclear experimental de la Universidad de Harvard, desempeñó allí un papel importante.

Fue contratado en mayo de 1943. Su misión era dirigir la construcción y el equipamiento de una instalación para la explosión de la primera bomba nuclear. Fue el encargado de realizar la última inspección de la bomba en la plataforma, justo antes de que se produjera la explosión.

En la madrugada del 16 de julio de 1945, instantes después de la explosión, que tuvo lugar en la Jornada del Muerto, un desierto distante unos 200 kilómetros de Alamogordo (Nuevo Méjico), Bainbridge felicitó a Oppenheimer y a los otros testigos presentes; acto seguido, les dijo: "Ahora somos todos unos hijos de puta". Oppenheimer comentaría más tarde que ésa fue la observación más profunda de las que se habían hecho justo después de la explosión. 
De vuelta a Harvard, Bainbridge adoptó una posición contraria a las armas nucleares y favorable a su control. Cuando Wendell Furry, un colega del Departamento de Física, fue atacado por el senador McCarthy, Bainbridge se volcó en su defensa.

Tuve el privilegio de tener a Bainbridge como profesor de Física Nuclear en el curso 1960-61, y lo recuerdo como un hombre muy amable y modesto. Antes de la guerra, en 1936, había construido un ciclotrón que fue considerado el mejor de los existentes y, como tal, requisado para Los Álamos. Después de la guerra dirigió la construcción de un nuevo ciclotrón, en Harvard, que todavía sigue funcionando. Lo utilizan los médicos del Massachusetts General Hospital para tratamientos clínicos e investigaciones de terapias con haces de protones. 